\title{
COMBINING SYSTEM DYNAMICS AND DISCRETE EVENT SIMULATIONS - OVERVIEW OF HYBRID SIMULATION MODELS
}

\author{
MSc Bojan Jovanovski * \\ Ss. Cyril and Methodi University, Faculty of Mecahical Engineering, Skopje, Macedonia \\ Dr Robert Minovski \\ Ss. Cyril and Methodi University, Faculty of Mecahical Engineering, Skopje, Macedonia \\ Dr Siegfried Voessner \\ Institute of Engineering and Business Informatics, TU Graz, Austria \\ Dr Gerald Lichtenegger \\ Institute of Engineering and Business Informatics, TU Graz, Austria
}

Simulation and modelling has been widely accepted as one of the most important aspects of the Industrial engineering. The application and use of simulation models has grown exponentially since the 1950' until today. Over the years, the complexity of the simulated aspects has been adapted to the complexity of the analysed cases which has risen proportionally too. That is why techniques used many years ago, can often not give an adequate representation of the real world any more. For that reason, we propose to use hybrid simulation models, which are a combination of simulation paradigms in order to cope with this problem. In this paper, we will give an overview of selected researches and applications with an emphasis on Discrete Event Simulation and System Dynamics, as one of the core simulation based techniques in that area.

Key words: Hybrids, Models, Simulation of models, System dynamics, Discrete-event simulation

\section{INTRODUCTION}

The advances in Industrial Engineering (IE) have gone a long way since the early beginnings and the experiments of Taylor, Gilbreth, Babbage, Towne and others. Not so much in the area of the field, but in the direction of tackling even the smallest details possible. In order to do this the complexity of the problems grew, with that the data needed to be obtained and processed was also getting bigger. The computers played huge factor in keeping the Industrial Engineering alive and constantly being in trend. Not only because of the hardware possibilities and the calculations that could have been made now, but also from the point of view that many software packages have been developed in order to solve some kind of an IE problem. There are solutions for finding an optimal layout, managing production processes, tackling ergonomic issues, calculating cost/profit etc. (the intention is not to name vendors here).
Simulation and modelling has been widely accepted as one of the most important aspects of the Industrial Engineering. The application and use of the simulation models has grown exponentially since the 50' until today. This is mainly because of the advances in the computation field, but also because of the increased number (percentage) of acceptance by the academia and the industry (Robinson 2004a). The complexity of the simulated issues has been adapted to the complexity of the real world cases and has risen proportionally. Many of the tools and techniques used many years ago can not present the level of details that is needed today in some cases. One of the theses for future trends in the field of simulation by Robinson (2004) is that in order to deal with this, a combination of techniques would be required. Also, in (Banks et al. 2003) few of the experts asked for bigger accent to be put in interoperability of simulation software. In that direction, the best from the selected techniques would be taken and they would complement each other, resulting in the synergy factor. 
In this paper, a comparison and combination of System Dynamics and Discrete Event Simulation (DES) will be presented. At the end one research example will be presented, showing why and when this should be done.

\section{SYSTEM DYNAMICS}

System Dynamics (SD) is a relatively new technique that has been populated in the last 20 years. The basic principle underlying system dynamics is that the structure of a system determines its behaviour over time (Forrester 1968; Sterman 2006). SD is all about the whole and looking at the system as a unit. In normal cases, a lot of people use the divide-and-conquer system in order to solve complex problems. The philosophy of SD is that every element is connected somehow with other element(s) and those relationships determine how the system performs over time. It is best used when modelling very complex systems that are very hard to perceive and understand.

There are two main approaches that help define a SD model. The first one is the causal loops (and feedback loops), which are widely spread and very useful. Most of the time, they are the first step in developing a SD model, helping in the conceptualisation. The second tool is the stock and flow diagrams, which aid to describe the model using data. The easiest way to describe this is to think of models like system of water tanks with pipes and valves.

In the research conducted by Helal et al. (2007) they have stated that "using SD at the operational level of the manufacturing system has failed to offer the needed granularity (Godding et al., 2003; Barton et al., 2001; Baines and Harisson, 1999; Bauer et al., 1982) [03, 07, 08]. The same was observed by Choi et al. (2006) who could not use SD to model the performance of the individual processes in a software development system". In (Özgün \& Barlas 2009) the authors needed to increase the values of some variables by tenfold in order for SD to "capture" them and for the model to make sense.

In addition, while SD permits the study of the stability of the system over the long range, the trends of behaviour that it generates do not indicate what specific actions to be made and at what values of the action parameters. Such specifications require more detailed considerations that SD does not seem to work with, while DES has been effective at.

\section{DISCRETE EVENT SIMULATION}

DES is a more widely established simulation technique (Banks et al. 2004). "The system is modelled as a series of events, that is, instants in time when a state-change occurs", (Robinson 2004). The models are stochastic and generally represent a queuing system. From the beginning until now, the models are based on a specific code that manages the simulation.

At the beginning, DES was developed and used in the manufacturing sector. But, as the times have changed, so have the areas where DES has found its applicability (hospitals, public offices, document management etc.) Still, the main advantages and principles have never changed no matter if the simulated entities are products, people, documents etc. (Law 2006; Banks 1998).

\section{COMPARISON}

The SD and DES are very different approaches when trying to model a situation and there are distinctive communities that follow each, respectively. Little bit inspired by the title of Sherwood (2002), the following comparison will be made in order to clarify some things. If a task of analysing a forest is given to these two types of modellers, the SD modellers will try to look at the forest from above, or from far away. They will look at the landscape, see how the trees are spread and grouped, analyse the types of trees etc. Meanwhile, the DES modellers will try to go in the forest and search in it, look at every tree as an entity, the leaves of the trees, the structure of the trees etc. Having this in mind, it was not very difficult to accept SD a technique for the attempt to model strategic decisions and use DES for the operational processes and decisions. Based on the work of Chahal \& Eldabi (2008c) and Lane (2000) a meta-comparison of both approaches is shown in Table 1.

There are numerous articles that describe and compare these techniques, particularly. Maybe one of the first attempts was done by Ruiz-Usano et al. (1996) and before that Crespo-Márquez et al. (1993) concentrating on discrete vs. continues systems. All of them give some kind of proposition or direction what technique is most suitable in which cases. Most of them (Brailsford \& Hilton 2001; Özgün \& Barlas 2009; Sweetser 1999; Huang et al. 2004; Wakeland \& Medina 2010) share the idea of the authors, presented 
earlier that SD is more suitable when modelling a system and analysing it as whole and DES when more details are needed for the better representation. The researches have been mainly focused on developing two same models in the different approaches and analysing and sharing the results (Robinson \& Morecroft 2006; Crespo-Márquez et al. 1993; Wakeland \& Medina 2010; Johnson \& Eberlein 2002). Tako \& Robinson (2008) have gone a step further and have analysed a model building process by five SD and five DES modellers on a same situation- a prison population problem. One of the detailed and structured comparison has been done by Chahal \& Eldabi (2008), dividing the analysis in more than thirty categories and explaining every one of them. There are even researches that deal with the third possible option when simulating (e.g. a supply chain) - simulation with agents and compare that along the previous two (Owen et al. 2008).

Table 1: Meta-comparison of two approaches

\begin{tabular}{|c|c|}
\hline DES & SD \\
\hline \multicolumn{2}{|c|}{ Problem } \\
\hline $\begin{array}{l}\text { Seeking to understand the imapct } \\
\text { of randomness on the system }\end{array}$ & $\begin{array}{l}\text { Aiming to understand the feedback within the } \\
\text { system and its impact }\end{array}$ \\
\hline \multicolumn{2}{|c|}{ Scope } \\
\hline Operational & Strategy / Policy \\
\hline \multicolumn{2}{|c|}{ System } \\
\hline $\begin{array}{l}\text { High level of detail that physically } \\
\text { represents the system (detail complexity) }\end{array}$ & $\begin{array}{c}\text { More macro level of detail that summarises the } \\
\text { system (dynamic complexity) }\end{array}$ \\
\hline \multicolumn{2}{|c|}{ Methodology } \\
\hline Process view & Systems view \\
\hline \multicolumn{2}{|c|}{ Philosophy } \\
\hline Randomness & Feedback \\
\hline
\end{tabular}

\section{COMBINING TWO MODELLING TECHNIQUES}

There are couple of examples where the idea of hybrid models has been taken and proved useful, especially combining SD and DES. They will be analysed according the area/industry for which the model was created, how the models are connected, to which level this was applied in the organization, are the models dependentlindependent and the format of the hybrid model. In the next section, we will share our insights regarding each of these issues and present you an example of a hybrid model being developed in mean time.

\section{Area/industry of application}

In the manufacturing industry, there is a good example for modelling hierarchical production systems (Venkateswaran et al. 2004; Venkateswaran $\&$ Son 2005). The authors are concentrated on the production and production related elements, and have developed a SD model for the longterm plans (developed by the "Enterprise-level decision maker") and short-term plans (developed by the "Shop-level decision maker"). In the paper (Rabelo et al. 2005) the authors have also examined a manufacturing enterprise, where they used SD to simulate a financial (reinvestment) policy and DES to simulate the production process of one machine. They have represented the number of machines in the SD model, so by "multiplying" this variable with the output of the DES process they can generate the production output of the enterprise. Based on the framework of (Helal et al. 2007), same has been tested and a hierarchical production model has been developed (Pastrana et al. 2010).

In the recent decade, the healthcare management has been seen as a very interesting field for the industrial engineers (the Institute of Industrial Engineers <www.iienet.org> have classified Healthcare Management in the same importance as Lean \& Six Sigma, Supply Chain Management, Ergonomics, Quality systems etc. and some universities have a special IE curriculum for Healthcare management, e.g. TU Eindhoven <www.tue.nl>). This interest has also been shown in using the simulation for tackling issues in the healthcare. Chahal and Eldabi (2008a) have distinguished three formats how 
the models inside a hybrid mode can communicate: Hierarchical, Process- Environment and Integrated format. Later they have suggested a framework for hybrid simulation in the healthcare (Chahal \& Eldabi 2010). In the work of Brailsford et al. (2010) the authors used the hybrid models to represent two case. The first one is when the DES model simulates a process of a patient being examined with a whole configuration of a hospital, while the SD simulates the community and how a specific disease would spread. In the second case, the DES was used to simulate operations of a contact centre, and SD to simulate demographic changes of the population being examined.

The use of hybrid modelling has found its applicability in the civil engineering as well (PeñaMora et al. 2008; SangHyun Lee et al. 2007; Alvanchi et al. 2009) dealing with problems that are more complex to be solved with independent simulation models or project management tools. One of the few advantages that the authors found with this approach is the benefit of proposals for improvement they got from the models. In the same direction as the previous two papers, Martin and Raffo (2001) have also suggested a hybrid approach in the software industry. They have worked on an issue that can be managed with project management software as well, but they argue that the benefit of the hybrid simulation is the experimentation that can be done. The use of agent-based modelling and SD as hybrid architecture can be also adapted for the automotive industry (Kieckhafer et al. 2009).

\section{Type of connection}

Combining the two different models in one hybrid one is one of the most important thing in this whole process. This defines also how the models will communicate, share data, behave at a certain time point etc. Back in the 1999 there were two papers that stress out the possibilities and the advantages when using HLA (High Level Architecture) to combine two or more models (Schulze 1999; Davis \& Moeller 1999). Some research done so far has employed this tool in order to combine their models (Venkateswaran et al. 2004; Rabelo et al. 2003; Alvanchi et al. 2009). Clearly, the benefits are enormous, but also the effort, time and the technicality when using this approach. Some have used a more usual ways to do this, like Excel and Visual Basic for Applications (Brailsford et al. 2010). There are even cases where a specific research has been conducted in order to define a generic module in order for SD and DES models to communicate and function (Helal et al. 2007).

There are even examples where the modellers have a single software solution (Anylogic, <www. xjtek.com>) and combined a DES model with differential equations (Marin et al. 2010). Maybe it is not as same as the rest of the cases, but is worth mentioning as an approach.

\section{Scope of the hybrid model}

In this section we would like to address at what scope is the hybrid model applied inside one area/organization; whether the hybrid model is about whole organization, two different functional areas inside organization, only one functional area etc. For example, the work of Brailsford et al. (2010) has two different cases, but both use DES to simulate inner situations (hospital and calling centre operations), while SD simulates very broad scenarios (whole community or population demographics). In the case of (Martin \& Raffo 2001) the model is a representation of a project being under away. Rabelo et al. (2005) have modelled two different functional areas - SD for the decisions concerning allocation of the financial resources (of the plants) and DES for operational decisions of the plant (number of machines, people etc.). In the case of (Venkateswaran et al. 2004), the whole hybrid model is about the production in the enterprise; SD for the aggregate-planning level and DES for detailed-scheduling level.

\section{Dependentlindependent models inside hybrid model}

The intention of the authors was to distinguish if the singular models inside the hybrid one are independent or dependent on each other. The idea was that maybe two different modellers can model their own model "independently" and then combine the model, which is thought of as very practical and less time consuming. This was very hard to distinguish during the research of the papers, because there is not so specific information regarding this issue. The authors have made experiments by themselves regarding this and have successfully paired two independent models. 


\section{Type of hybrid model format}

Chahal and Eldabi (2008a) have distinguished three formats how the models inside a hybrid model can communicate: Hierarchical, Process - Environment and Integrated format.

The works of (Venkateswaran et al. 2004; Rabelo et al. 2005; Rabelo et al. 2003; Pastrana et al. 2010) have a hierarchical model. (Brailsford et al. 2010) and (Martin \& Raffo 2001) both deal with processes and how the environment deals with the changes that they bring. In (Brailsford et al. 2010) the authors argue that no one until now has achieved to develop a hybrid model by the Integrated format, but given the progress of the development of hybrid models, the gap is getting narrower.

\section{EXAMPLE / CASE}

For the research that is going on right now, we are in a process of developing a hybrid model, based on the case of one production enterprise.
This was not possible to be done in DES only environment, and when we experimented only with SD we did not get the needed detail level of the production.

Because of the nature of the situation, we are developing two separate models. One SD model that will represent the top management decision about how many sales personal need to be (hired/fired) and one DES model about the process of production of the products been sold. The models are of hierarchical format according the classification of (Chahal \& Eldabi 2008a) and aid each other so that the number of sales personnel is according the demand, but also according the production capacity (from the DES model). The connection was established using the built-in functions of the used software (Plant Simulation for DES and PowerSim for SD) and we used Excel as data storage media through the simulation runs. The functioning of the hybrid model is presented in Figure 1.

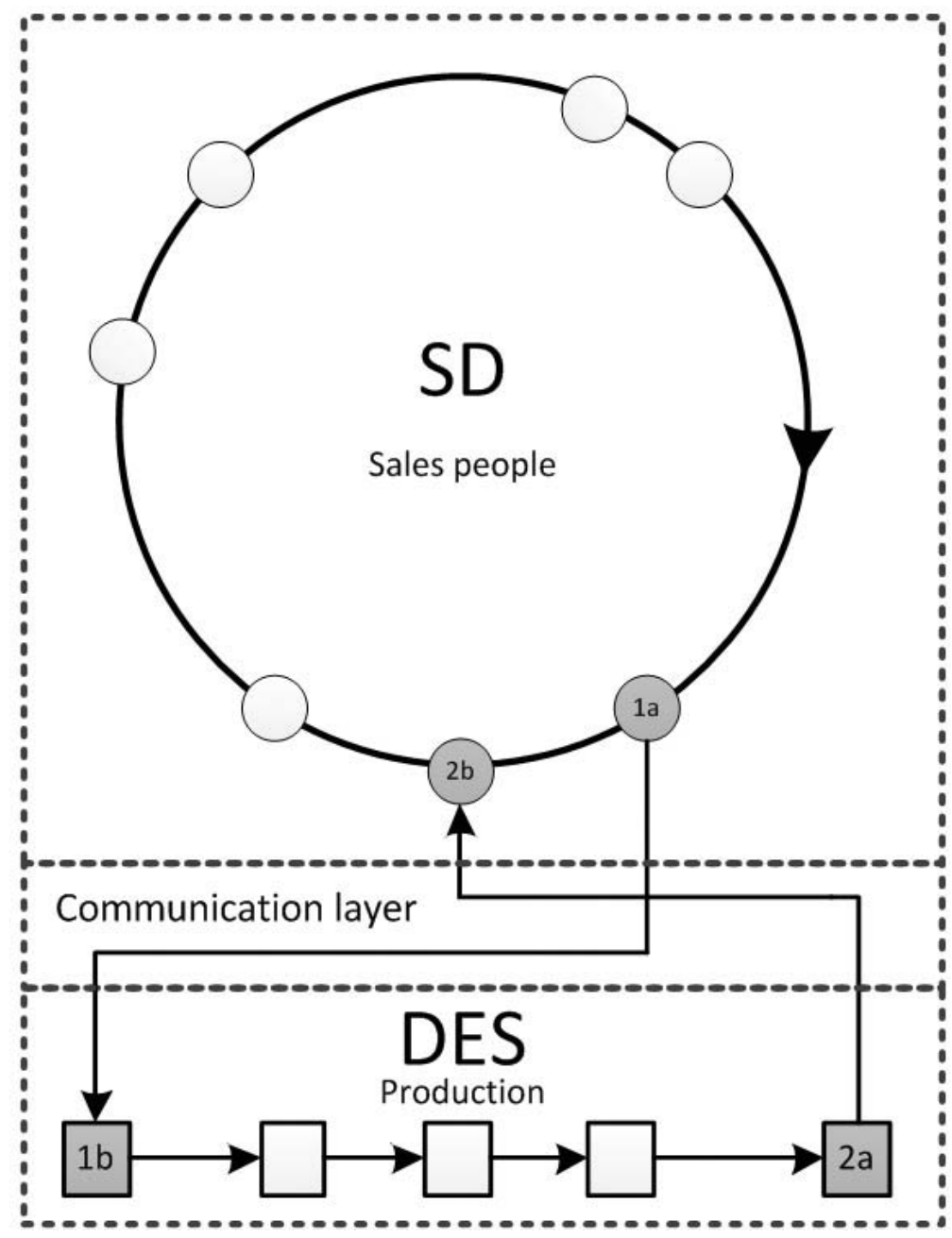

Figure 1: Structure of the hybrid model 
The model works in that way that the SD model runs and triggers the DES model (the production) and sends the information regarding the demand. After the production cycle is finished, it sends back to the SD model the number of produced products. This information is received and taken in the SD model in order to calculate the possible sales that is one of the main inputs for determining the number of sales people (which was the initial goal of the simulation model).

\section{CONCLUCSIONS}

This paper summarizes and analyses different hybrid simulation models from selected papers. This is a relatively new area and only handful of research papers exist. Based on the papers and the authors view, the need for this kind of models is very justified and will be even more important in the near future. In order to get the most appropriate and convincing representation of the real world, the suitable modelling approach should be used. Because we try to simulate very complex scenarios, the need for hybrid simulation and modelling is inevitable. For our needs, the usage of System Dynamics and Discrete Event Simulation has been proven most suitable.

\section{ACKNOWLEDGEMENTS}

This research is supported by a MacedonianAustrian research project titled as "Joint simulation model for strategic decision support" funded by both Governments.

\section{REFERENCES}

1) Alvanchi, A., Lee, S. \& AbouRizk, S.M., 2009. Modeling Architecture for Hybrid System Dynamics and Discrete Event Simulation. ASCE Conference Proceedings, 339(41020), p.131.

2) Abu Gaben, M., Krčevinac, S., Vujošević, M.: Modelujući sistemi u optimizaciji, (2007) Journal ofApplied Engineering Science (Istraživanja i projektovanja za privredu), no. 18, p. 37-47

3) Baines T, Harrison D. 1999. An opportunity for system dynamics in manufacturing system modeling. Production Planning and Control 10(6): 542-552

4) Banks, J. et al., 2004. Discrete-Event System Simulation (4th Edition), Prentice Hall.

5) Banks, J., Hugan, J. \& Lendermann, P., 2003. The future of the simulation industry. In E. S. Chick, P. J. Sánchez, D. Ferrin, and D. J. Morrice, ed. Proceedings of the 2003 Winter Simulation Conference. pp. 2033-2043.
6) Banks, J. ed., 1998. Handbook of simulation, Wiley Online Library.

7) Barton J, Love D, Taylor G. 2001. Evaluating design implementation strategies using simulation. International Journal of Production Economics 72: 285-299

8) Bauer C, Whitehouse G, Brooks G. 1982. Computer simulation of production system: Phase I. Technical Report COE No. 82-83-1. The University of Central Florida, Orlando, FL

9) Brailsford, S.C., Desai, S.M. \& Viana, J., 2010. Towards the holy grail: combining system dynamics and discrete-event simulation in healthcare. In B. Johansson et al., eds. Proceedings of the 2010 Winter Simulation Conference. pp. 2293-2303.

10) Brailsford, S.C. \& Hilton, N., 2001. A comparison of discrete event simulation and system dynamics for modelling health care systems. Food in Canada, pp.1-17.

11) Curović, D., Vasić, B., Popović, V., Curović, N.:Ekspertsko planiranje proizvodnje, (2008) Journal of Applied Engineering Science (Istraživanja i projektovanja u privredi), no. 20, p.49-57

12) Chahal, K. \& Eldabi, T., 2010. A generic framework for hybrid simulation in healthcare. In Proceedings of the 28th International Conference of the System Dynamics Society. System Dynamics Society.

13) Chahal, K. \& Eldabi, T., 2008a. Applicability of hybrid simulation to different modes of governance in UK healthcare. In S. J. Mason et al., eds. Proceedings of the 2008 Winter Simulation Conference. pp. 1469-1477.

14) Chahal, K. \& Eldabi, T., 2008b. System Dynamics and Discrete Event Simulation: A Meta-Comparison. In the proccedings of UK Operational Reserach Society Simulation Workshop. pp. 189-197.

15) Chahal, K. \& Eldabi, T., 2008c. Which is more appropriate: A multiperspective comparison between System Dynamics and Discrete Event Simulation. In Proceedings of the European and Mediterranean Conference on Information Systems. Al Bustan Rotana Hotel, Dubai

16) Choi K, Bae D, Kim T. 2006. An approach to a hybrid software process simulation using the DEVS formalism. Software Process: Improvement and Practice 11(4): 373-383 
17) Crespo-Márquez, A., Usano, R.R. \& Aznar, R.D., 1993. Continuous and Discrete Simulation in a Production Planning System. A Comparative Study. In E. Zepeda \& J. A. D. Machuca, eds. Proceedings of the 1993 International System Dynamics Conference. System Dynamics Society, p. 8p.

18) Davis, W. \& Moeller, G.L., 1999. The High Level Architecture: is there a better way? In P. A. Farrington et al., eds. Proceedings of the 1999 Winter Simulation Conference. pp. 1595-1601.

19) Forrester, J.W., 1968. Principles of Systems, Pegasus Communications.

20) Godding G, Sarjoughian H, Kempf K. 2003. Semiconductor supply network simulation. The Winter Simulation Conference, Dec 710, New Orleans, LA

21) Helal, M. et al., 2007. A methodology for Integrating and Synchronizing the System Dynamics and Discrete Event Simulation Paradigms. Industrial Engineering.

22) Huang, P. et al., 2004. Utilizing simulation to evaluate business decisions in sense-andrespond systems. Simulation, (2000).

23) Johnson, S. \& Eberlein, B., 2002. Alternative modeling approaches: a case study in the oil \& gas industry. In 20th System Dynamics Conference, Palermo, Italy.

24) Kieckhafer, K. et al., 2009. Integrating agentbased simulation and system dynamics to support product strategy decisions in the automotive industry. Proceedings of the 2009 Winter Simulation Conference, pp.1433-1443.

25) Lane, D. C., 2000. You Just Don't Understand Me: Modes of failure and success in the discourse between system dynamics and discrete event simulation.LSE OR Working Paper 00.34.

26) Law, A., 2006. Simulation Modeling and Analysis, Mcgraw Hill Higher Education.

27) Lee, SangHyun, Han, S. \& Peña-Mora, F., 2007. Hybrid System Dynamics and Discrete Event Simulation for Construction Management. Computing in Civil Engineering 2007, (May 2011), p.29.

28) Marin, M. et al., 2010. Supply chain and hybrid modeling: the panama canal operations and its salinity diffusion. In B. Johansson et al., eds. Proceedings of the 2010 Winter Simulation Conference. pp. 2023-2033.
29) Martin, R. \& Raffo, D., 2001. Application of a hybrid process simulation model to a software development project. Journal of Systems and Software, 59, pp.237-246.

30) Meadows, D.H., 2008. Thinking in Systems: A Primer D. Wright, ed., Chelsea Green Publishing.

31) Owen, C., Love, D. \& Albores, P., 2008. Selection of simulation tools for improving supply chain performance. Business, pp.199-207.

32) Pastrana, J. et al., 2010. Enterprise scheduling: Hybrid and hierarchical issues. In $\mathrm{B}$. Johansson et al., eds. Proceedings of the 2010 Winter Simulation Conference. IEEE, pp. 3350-3362.

33) Peña-Mora, F. et al., 2008. Strategic-Operational Construction Management: Hybrid System Dynamics and Discrete Event Approach. Journal of Construction Engineering and Management, 134(9), p.701.

34) Rabelo, L. et al., 2003. A Hybrid Approach to Manufacturing Enterprise Simulation. Proceedings of the 2003 International Conference on Machine Learning and Cybernetics; wintersim, 2, pp.1125-1133.

35) Rabelo, L. et al., 2005. Enterprise simulation: a hybrid system approach. International Journal of Computer Integrated Manufacturing, 18(6), pp.498-508.

36) Robinson, S., 2004a. Discrete-event simulation: from the pioneers to the present, what next? Journal of the Operational Research Society, 56(6), pp.619-629.

37) Robinson, S., 2004b. Simulation: The Practice of Model Development and Use, John Wiley\& Sons Ltd.

38) Robinson, S. \& Morecroft, J., 2006. Comparing discrete-event simulation and system dynamics: modelling a fishery. In Proceedings of the Operational Research Society Simulation Workshop. pp. 137-148.

39) Ruiz-Usano, R. et al., 1996. System Dynamics and Discrete Simulation in a Constant Work-in-Process System: A Comparative Study. In G. P. Richardson \& J. D. Sterman, eds. Proceedings of the 1996 International System Dynamics Conference. System Dynamics Society, pp. 457-460.

40) Schulze, T., 1999. On-line data processing in simulation models: new approaches and possibilities through HLA. In P. A. Farrington et al., eds. Proceedings of the 1999 Winter Simulation Conference. pp. 1602-1609. 
41) Spasojević, V., Klarin, M., Curović, D.: Dimenzije menadžmenta kvalitetom isporučioca u industrijskim preduzećima Srbije, (2009), Journal of Applied Engineering Science (Istraživanja i projektovanja u privredi), no. 23-24, p. 67-70

42) Sherwood, D., 2002. Seeing the Forest for the Trees: A Manager's Guide to Applying Systems Thinking, Nicholas Brealey Publishing.

43) Sterman, J.D., 2006. Business Dynamics, McGraw-Hill.

44) Sweetser, A., 1999. A Comparison of System Dynamics ( SD ) and Discrete Event Simulation ( DES ). System, p.8.

45) Tako, A.A. \& Robinson, S., 2008. Model building in System Dynamics and Discreteevent Simulation: a quantitative comparison. Analysis.

46) Venkateswaran, J. \& Son, Y.J., 2005. Hybrid system dynamic-discrete event simulationbased architecture for hierarchical production planning. International Journal of Production Research, 43(20), pp.4397-4429.
47) Venkateswaran, J., Son, Y.J. \& Jones, A., 2004. Hierarchical production planning using a hybrid system dynamic-discrete event simulation architecture. Proceedings of the 2004 Winter Simulation Conference, pp.1094-1102.

48) Wakeland, W.W. \& Medina, U.E., 2010. Comparing Discrete Simulation and System Dynamics: Modeling an Anti-insurgency Influence Operation. Proceedings of the 28th International Conference of the System Dynamics Society, (1991), pp.1-23.

49) Özgün, O. \& Barlas, Y., 2009. Discrete vs. Continuous Simulation: When Does It Matter? Proceedings of the 27th International Conference of The System Dynamics Society, (06), pp.1-22

Paper sent to revision: 27.08.2012.

Paper ready for publication: 26.09.2012. 